\title{
Psychosocial Aspects of Diabetic Patients: A Pilot Study In Saudi Arabia
}

\author{
Waleed Alamoudi, Osamah Alsulimani, Alaa Babeer, Sahar Bukhary, Nadia Al-Hazmi* \\ Department of Oral Medicine, Department of Oral Biology, King Abdulaziz University Faculty of Dentistry, Jeddah, Saudi Arabia. PO Box 80200, Jeddah 21589.
}

Received: October 6, 2016; Accepted: October 25, 2016; Published: November 03, 2016

*Corresponding author: Nadia Al-Hazmi, Assistant Professor, Department of Oral Medicine, Department of Oral Biology, King Abdulaziz University Faculty of Dentistry, Jeddah, Saudi Arabia. PO Box 80200, Jeddah 21589. E-mail: nalhazmi@kau.edu.sa

\begin{abstract}
Introduction: In Saudi Arabia, diabetes affects one in four individuals. It greatly impacts on their Quality of Life and is a heavy burden on the country. Many patients are not compliant with their treatments which leads to high morbidity.
\end{abstract}

Aim: The goal of this work was to assess the perceived problems with diabetes, their distress, and the relative fatalism felt by affected individuals.

Methods: The Problem Areas in Diabetes (PAID) scale, the Diabetes Distress Scale (DDS), and the Diabetes Fatalism Scale (DFS) were used after translating them to Arabic. They were distributed anonymously to patients with diabetes and were then analyzed.

Results: Results of the PAID questions showed that the main concerns displayed by diabetic patients include complications of the condition, adverse effects of low blood sugar levels on health and the effect of glycemic control on their mood. Results to the DDS showed that the main stressor for patients is the constant feeling that they are unable to control their regiment well enough. The DFS results showed that patients feel that diabetes interferes with their lives causing distress and frustration, and they feel upset about it.

Conclusion: Whether they vocalize their feelings or not, diabetic patients perceive this disease as a weighty and difficult condition with which they must live. Understanding their concerns can enable the dental team in appeasing fears, catering to their patients' frustrations and ultimately helping them cope and take control of their oral and overall health.

Keywords: Diabetes; PAID; DDS; DFS; complications; perception; patients;

\section{Introduction}

Diabetes mellitus is one of the common chronic diseases that affects a wide range of the global population [1]. Worldwide, 347 million people have diabetes [2]. In Saudi Arabia, diabetes mellitus has a high prevalence (23.7\%) [3]. Diabetes is known to have an impact on life expectancy and quality of life because it has prolonged and severe complications, and this causes a great deal of worry and fear in the affected patients [4,5]. In 2008, Fisher and colleagues defined diabetes distress as "patient concerns about disease management, support, emotional burden, and access to care" [6]. Previous work has proposed that psychological distress occurring in patients with diabetes is overwhelmingly related to the struggle of keeping a strict daily regimen and to concerns about its complications [7]. Psychological distress can be a burden because it can suppress the self-care behaviors of patients, which can lead to compromised glycemic control $[8,9]$. Fisher and colleagues reported that in the US, diabetes distress occurs in association with inadequate physical exertion, inadequate glycemic control, a poor dietary plan, and a negative attitude toward medication and that outside the US, it occurs in association with inadequate glycemic control, overweight, signs of depression, and poor quality of life [10]. Living with this disease can be difficult and challenging; in the face of such exacting and complicated self-care directives, patients may become frustrated, irritated, and weighed down [11]. Sometimes, they may become fatalistic: According to Powe and Weinrich, fatalism is defined as "a complex psychological cycle characterized by perceptions of hopelessness, worthlessness, meaninglessness, powerlessness, and social despair" [12]. Fatalism is a worldwide belief also shared by Muslims [13]. Some fatalistic patients believe they are incapable of managing their condition [14]. Poor management and the occurrence of complications may be attributed to fatalism by these patients, resulting in the loss of willingness to commit to their instructions [15]. Sometimes, such fears are unwarranted and may add to the burden of diabetes. With such complicated changes to normal life, many patients may feel overwhelmed, becoming unwilling to follow a diabetes regimen, and this in turn increases the risk of depression [16].

Recognizing signs of stress and frustration in patients can go a long way in helping them deal with their condition. A community that rallies around the concerns of such patients can greatly improve their health outcomes [17]. The dental team is part of the community and often sees the patients on a regular basis. They can address concerns and appease fears which in turn can help the patient cope and take charge of their health [18].

\section{Materials and Methods}

The purpose of this study was to evaluate psychosocial problems faced by diabetic patients in Saudi Arabia. In 
order to evaluate such problems, we used three well-known questionnaires that assess how patients perceive their condition, how it impacts their lives, and whether socio-economic factors such as sex, marital/family status, and level of education affects such perceptions.

\section{Preparation of Questionnaires}

Three previously validated questionnaires were used: Problem Areas in Diabetes (PAID), Diabetes Distress Scale (DDS), and Diabetes Fatalism Scale (DFS) $[6,19,20]$. The PAID is a 20item questionnaire where statements are given a score ranging from 0 (not a problem) to 4 (a serious problem). The DDS is a 17item questionnaire that uses a Likert scale with each item, scored from 1 (no distress) to 6 (serious distress). The DFS is a 12 -item questionnaire that also uses a Likert scale, with scores ranging from 6 (strongly agree) to 1 (strongly disagree).

A native Arabic speaker with high English proficiency and a medical background translated the questionnaires from English to Arabic. Bilingual experts evaluated the translations for logic and clarity. The questionnaires were then given to a native English speaker with high Arabic proficiency to translate back to English. The final English versions were compared to the original English questionnaires for accuracy. Arabic questionnaires were pre-tested using a focus group similar to the final sample group to ensure all questions were clear and unambiguous. Some cultural adaptation was applied to the DFS to adhere to the country's homogeneous Muslim population.

\section{Sampling and inclusion criteria}

Questionnaires were distributed by two general dentists to a randomized sample of patients with diabetes that attended the World Diabetes Day Awareness Campaign held in the city of Jeddah. Questionnaires were coded and remained anonymous. Patients of both sexes were included. Incomplete questionnaires and patients less than 18 years of age were excluded. A total of 218 questionnaires were distributed.

\section{Statistical Analysis}

Simple descriptive statistics were used to describe demographics. On account of the complexity of the questionnaires and their shared themes, Principal Component Analysis (PCA), was the method of choice in analyzing the results. This enabled us to convert a set of observations into 'principal components'.

The PAID contained statements about four domains of quality of life: emotional distress, complications, satisfaction, and lack of social support. The DDS contained three domains: coping with the disease, the doctor's role, and lack of social support. Finally, the DFS contained three domains: emotional distress, religious and spiritual coping issues, and perceived self-efficacy issues. Because the PAID questionnaire had 4 subsets, it is referred to as Q1D1/2/3/4 (Table 1) where "Q" signifies "questionnaire", $\mathrm{D} 1 / 2 / 3$ and 4 , signify the respective "domains"; the DDS is referred to as Q2D1/2/3 (Table 2), and the DFS as Q3D1/2/3 (Table 3). Based on PCA, the domains of all three questionnaires were grouped according to the consistency of responses and the meanings of the questions, meaning that they highlighted consistency throughout the domains.

Finally, both the $t$-test and one-way ANOVA were used to compare differences in demographics among continuous domain variables in each of the three questionnaires. All factor domain measures were converted to a 100-point scale. Normality for all tests was evaluated after Kaiser normalization. Statistical significance was recognized when $\mathrm{p}<0.05$. The analysis was carried out using IBM SPSS version 20.

This study was approved by the Executive Board Ethical Committee Members of King Abdulaziz University Faculty of Dentistry and was in full accordance with the worldmedical Association Declaration of Helsinki.

\section{Results}

Of the questionnaires distributed, 21 were excluded from analysis because of discrepancies in completion; therefore, the final sample size was $n=197$. The participants were nearly

Table 1: Problem Areas in Diabetes questionnaire (Q1) statements assembled into themes (D1, D2, D3, and D4) referred to as Q1D1/2/3/4.

\begin{tabular}{|c|c|c|c|c|}
\hline & \multicolumn{4}{|c|}{ Component } \\
\hline & D1 & D2 & D3 & D4 \\
\hline 6- "Feeling depressed" & .788 & & & \\
\hline $\begin{array}{l}\text { 5- "Feeling deprivation regarding } \\
\text { food" }\end{array}$ & .774 & & & \\
\hline 7- "Feeling angry" & .757 & & & \\
\hline 3- "Feeling scared" & .712 & & & \\
\hline $\begin{array}{l}\text { 1- "Feeling overwhelmed by your } \\
\text { diabetes" }\end{array}$ & .676 & & & \\
\hline 9- "Not accepting your diabetes" & .594 & & & \\
\hline 15- "Feeling of guilt or anxiety" & .503 & & & \\
\hline $\begin{array}{l}\text { 2- "Feeling discouraged with } \\
\text { treatment plan" }\end{array}$ & & & & \\
\hline $\begin{array}{l}\text { 14- "Worrying about } \\
\text { complications" }\end{array}$ & & .791 & & \\
\hline $\begin{array}{l}\text { 12- "Worrying about low blood } \\
\text { sugar reactions" }\end{array}$ & & .700 & & \\
\hline $\begin{array}{l}\text { 8- "Concerned about food and } \\
\text { eating" }\end{array}$ & & .531 & & \\
\hline 13- "Coping with complications" & & .509 & & \\
\hline $\begin{array}{l}\text { 16- "Unsatisfied with diabetes } \\
\text { physician" }\end{array}$ & & & .799 & \\
\hline $\begin{array}{c}\text { 17- " Diabetes is taking up too much } \\
\text { energy" }\end{array}$ & & & .672 & \\
\hline $\begin{array}{l}\text { 10- "Mood related to your } \\
\text { diabetes" }\end{array}$ & & & .625 & \\
\hline 20- "Feeling burned out" & & & .609 & \\
\hline $\begin{array}{l}\text { 18- "Feeling alone with your } \\
\text { diabetes" }\end{array}$ & & & .561 & \\
\hline $\begin{array}{l}\text { 11- "Not having clear and concrete } \\
\text { goals" }\end{array}$ & & & .523 & \\
\hline 4- "Uncomfortable social situation" & & & & .725 \\
\hline $\begin{array}{l}\text { 19- "Feeling that others are not } \\
\text { supportive" }\end{array}$ & & & & .657 \\
\hline
\end{tabular}


equally distributed across the sexes, age ranges, and marital status (Table 4).

Our results showed that age was a factor that affected the level of worry and fear felt by diabetic patients towards complications of diabetes. In Q1D2, patients under 35 showed a significant difference in their worry of developing complications $(p=0.007)$ (figure 1).

Both gender and employment status played a role in the patient's perceived support from family or friends. In fact, in Q1D4, most patients who described little or no support from family and friends were female $(\mathrm{p}=0.002)$, and were unemployed or retired $(\mathrm{p}=0.003)$. Gender was also a significant factor in the patient's perceived difficulty in coping (Q2D1 and Q2D3) ( $p=$ 0.005) (Figure 2).

Marital status was found to affect the general satisfaction with the condition including the treatment regiments. In fact,

Table 2: Diabetes Distress Scale questionnaire (Q2) statements assembled into themes (D1, D2, and D3) referred to as Q2D1/2/3.

\begin{tabular}{|c|c|c|c|}
\hline & \multicolumn{3}{|c|}{ Component } \\
\hline & D1 & D2 & D3 \\
\hline $\begin{array}{l}\text { 11- "Feeling that I will end up with serious long- } \\
\text { term complications, no matter what I do" }\end{array}$ & .826 & & \\
\hline $\begin{array}{l}\text { 10- "Not feeling confident in my day-to-day ability } \\
\text { to manage diabetes" }\end{array}$ & .745 & & \\
\hline $\begin{array}{l}\text { 14- "Feeling overwhelmed by the demands of } \\
\text { living with diabetes" }\end{array}$ & .744 & & \\
\hline 8- "Feeling that diabetes controls my life" & .717 & & \\
\hline $\begin{array}{l}\text { 1- "Feeling that diabetes is taking up too much of } \\
\text { my mental and physical energy every day" }\end{array}$ & .679 & & \\
\hline $\begin{array}{l}\text { 3- "Feeling angry, scared and/or depressed when } \\
\text { I think about living with diabetes" }\end{array}$ & .633 & & \\
\hline $\begin{array}{l}\text { 12- "Feeling that I am not sticking closely enough } \\
\text { to a good meal plan" }\end{array}$ & .576 & & \\
\hline $\begin{array}{l}\text { 6- "Feeling that I am often failing with my } \\
\text { diabetes regimen" }\end{array}$ & .500 & & \\
\hline $\begin{array}{l}\text { 16- "Not feeling motivated to keep up my diabetes } \\
\text { self-management" }\end{array}$ & & & \\
\hline $\begin{array}{l}\text { 2- "Feeling that my doctor doesn't know enough } \\
\text { about diabetes an diabetes care" }\end{array}$ & & -.871 & \\
\hline $\begin{array}{l}\text { 9- "Feeling that my doctor doesn't take my } \\
\text { concerns seriously enough" }\end{array}$ & & -.869 & \\
\hline $\begin{array}{l}\text { 4- "Feeling that my doctor doesn't give me clear } \\
\text { enough directions on how to manage my diabetes" }\end{array}$ & & -.861 & \\
\hline $\begin{array}{l}\text { 15- "Feeling that I don't have a doctor who I can } \\
\text { see regularly about my diabetes" }\end{array}$ & & -.728 & \\
\hline $\begin{array}{l}\text { 7- "Feeling that friends or family are not } \\
\text { supportive enough of my self-care efforts } \\
\text { (planning activities that conflict with my schedule, } \\
\text { encouraging me to eat the 'wrong' foods)" }\end{array}$ & & & .873 \\
\hline $\begin{array}{l}\text { 17- "Feeling that friends or family don't give me } \\
\text { emotional support that I would like" }\end{array}$ & & & .735 \\
\hline $\begin{array}{l}\text { 13- "Feeling that friends or family don't } \\
\text { appreciate how difficult living with diabetes can } \\
\text { be" }\end{array}$ & & & .645 \\
\hline $\begin{array}{l}\text { 5- "Feeling that I am not testing my blood sugars } \\
\text { frequently enough" }\end{array}$ & & & \\
\hline
\end{tabular}

Table 3: Diabetes Fatalism Scale questionnaire (Q3) statements assembled into themes (D1, D2, and D3) referred to as Q3D1/2/3.

\begin{tabular}{|c|c|c|c|}
\hline & \multicolumn{3}{|c|}{ Component } \\
\hline & D1 & D2 & D3 \\
\hline $\begin{array}{l}\text { 3- "I get frustrated with having to live with } \\
\text { diabetes" }\end{array}$ & 0.874 & & \\
\hline $\begin{array}{l}\text { 2- "I feel down when I think about my } \\
\text { diabetes" }\end{array}$ & 0.855 & & \\
\hline $\begin{array}{l}\text { 4- "Diabetes is a disease that makes life more } \\
\text { difficult" }\end{array}$ & 0.841 & & \\
\hline $\begin{array}{l}\text { 1- "I get upset when I think about my } \\
\text { diabetes" }\end{array}$ & 0.823 & & \\
\hline 5- "Diabetes causes a lot of suffering for me" & 0.789 & & \\
\hline $\begin{array}{l}\text { 6- "trusting in God has helped me better deal } \\
\text { with my diabetes" }\end{array}$ & & 0.842 & \\
\hline $\begin{array}{l}\text { 8- "I believe God can completely cure my } \\
\text { diabetes" }\end{array}$ & & 0.812 & \\
\hline $\begin{array}{c}\text { 7- "I believe God does not give me more than } \\
\text { I bear" }\end{array}$ & & 0.735 & \\
\hline $\begin{array}{l}\text { 9- "I have prayed about my diabetes so I am } \\
\text { not going to worry about it anymore" }\end{array}$ & & 0.648 & \\
\hline $\begin{array}{l}\text { 11- "If I do everything my doctor tells me, I } \\
\text { can prevent the complications of diabetes like } \\
\text { blindness, amputations, kidney failure, etc" }\end{array}$ & & & -0.804 \\
\hline $\begin{array}{l}\text { 10- "I believe I am able to control my diabetes } \\
\text { the way my doctor expects" }\end{array}$ & & & -0.773 \\
\hline 12- "I believe that diabetes is controllable" & & & -0.701 \\
\hline
\end{tabular}

Table 4 - Demographic data.

\begin{tabular}{|c|c|c|c|}
\hline \multicolumn{2}{|c|}{ Demographic data } & Number & $\%$ \\
\hline \multirow{3}{*}{ Inclusion } & Excluded & 21 & 9.6 \\
\hline & Included & 197 & 90.4 \\
\hline & Total & 218 & 100 \\
\hline \multirow{3}{*}{ Sex: } & Female & 97 & 49.2 \\
\hline & Male & 100 & 50.8 \\
\hline & Total & 197 & 100 \\
\hline \multirow{3}{*}{ Age (years): } & $18-35$ & 98 & 49.7 \\
\hline & $>36$ & 99 & 50.3 \\
\hline & Total & 197 & 100 \\
\hline \multirow{3}{*}{ Marital status: } & Married & 104 & 52.8 \\
\hline & Single/Widowed & 93 & 47.2 \\
\hline & Total & 197 & 100 \\
\hline \multirow{3}{*}{ Job status: } & Employed & 79 & 40.1 \\
\hline & Unemployed/retired & 118 & 59.9 \\
\hline & Total & 197 & 100 \\
\hline \multirow{3}{*}{ Nationality: } & Non-Saudi & 53 & 26.9 \\
\hline & Saudi & 144 & 73.1 \\
\hline & Total & 197 & 100 \\
\hline \multirow{5}{*}{ Income (riyals): } & $<5000$ & 78 & 39.6 \\
\hline & $5000-10,000$ & 56 & 28.4 \\
\hline & $11,000-20,000$ & 45 & 22.8 \\
\hline & $>20,000$ & 18 & 9.1 \\
\hline & Total & 197 & 100 \\
\hline
\end{tabular}


marital status played a significant role in the results of several domains, including Q1D3, Q1D4, Q2D1 and Q2D3 showing a higher dissatisfaction and unhappiness among single patients (figure 3).

Interestingly, our results showed that nationality was a factor in how the patient felt towards their treating physician. In Q2D2, most patients who expressed dissatisfaction with their physician were Saudi, and when income per month was above 10,000 Saudi Arabian Riyals (approximately $\$ 2,650$ ), patients became religiously fragile, therefore adopting a more fatalistic outlook on their condition $(\mathrm{p}=0.004)$.

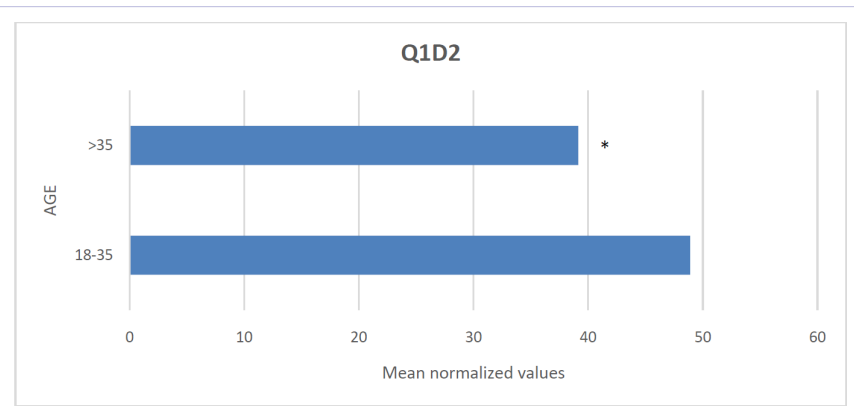

Figure 1: Patients under 35 were more worried about developing complications $(p=0.007)$.

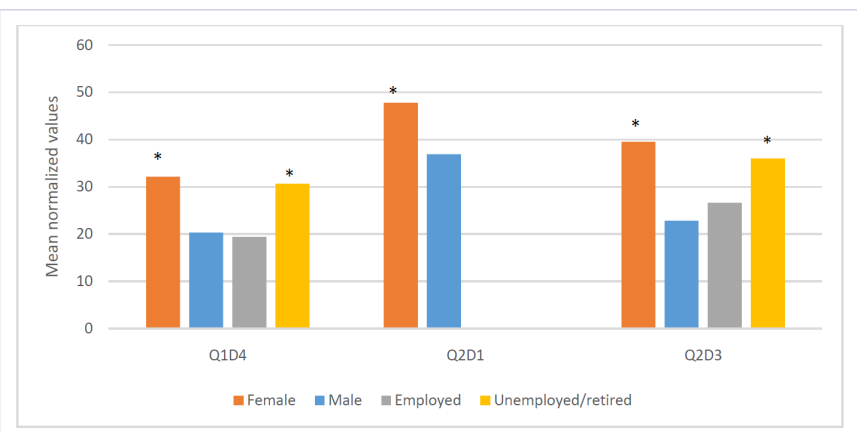

Figure 2: Perceived support from family or friends, and experienced difficulty in coping were higher in females and unemployed/retired patients.

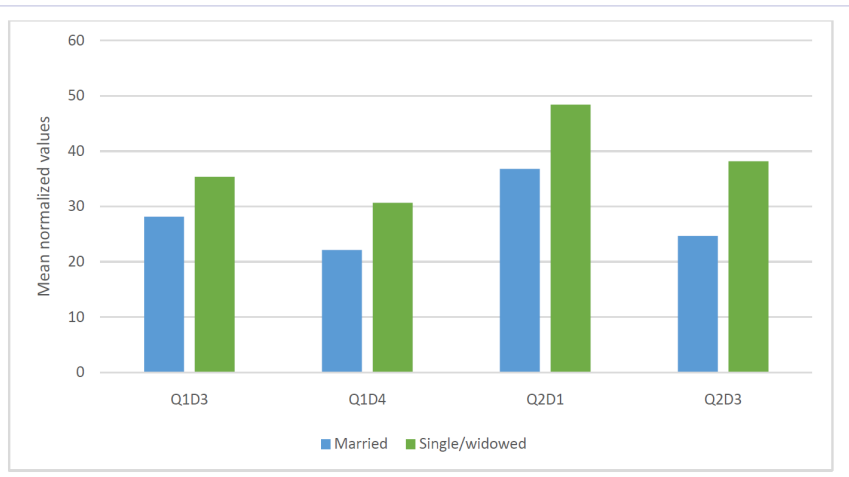

Figure 3: Marital status played a significant role in the results of several domains, showing a higher dissatisfaction and unhappiness among single patients.

\section{Discussion}

How a person views his/her chronic condition is dependent on many psychosocial factors. This in turn, impacts how the person deals with their conditions and the kind of attitude they adopt. In the past two decades, many experts have explored diabetes-related psychosocial illnesses [21,22]. For example, a condition such as depression that is brought about by the impacts of both biological and psychosocial stressors increases the risk of diabetes in healthy people [21]. Diabetes-specific stressors are associated with poor self-care and impaired glycemic control [19]. This in turn may increase the morbidity associated with diabetes which in turn adds a new multitude of stressors [23].

Consistent with previous studies, we found that one main stressor for patients are the complications of diabetes [24]. This was observed as increased emotional distress, as measured by the PAID questionnaire. The fear of developing complications and the feeling of not being able to be self-sufficient in managing diabetes were consistent with findings reported by Suliman et al. In 2010 at Al-Sharjah in the United Arab Emirates. The study by Suliman et al. Evaluated the relationship between distress and diabetes, and found that patient mental state affects control over diabetes. He concluded that mental management of these patients is a vital part in the management of diabetes [24].

Several studies have concluded that women with diabetes have a greater risk of depression [21, 25, 26]. Elisabeth et al. Reported in 2011 that "depression appeared to be more common in women than in men with type 2 Diabetes" [19]. One other study, however, reported greater depression in men, but increased levels of anxiety in women [27]. The fact that in our results gender played a significant role in the level of stress felt by the patient, lends to the need for more attention when treating female patients.

Egede and Ellis reported in 2009 that age was not significantly correlated with DFS scores [20]. In 2010, Fisher et al. Stated the same and that education level also was not correlated with DFS scores [10]. However, our findings oppose the above-mentioned results. This could easily be attributed to a variation of cultural behaviors. We also found a relationship between employment status and the level of distress, where distress was higher in unemployed or retired patients, and this may be attributed to loneliness or the decrease in income to a level that puts treatment out of reach and therefore increasing stress. This is consistent with findings by Taloyan et al., in 2010, who reported that unemployed/retired patients with type 2 diabetes, regardless of ethnicity, had the highest odds ratio for reporting poor general health [28]. However, among the socio-demographic variables of African Americans in a study by Spencer et al. In 2006, only living with others was positively correlated with higher PAID scores, which contrasts with our findings [29]. In Saudi Arabia, community is still very closely-knit and people co-live within extended families. This is the cultural norm. Faith also plays an important role in the Saudi community. It is interesting that with higher income, religious vulnerability sets in. This may be 
attributed to a more consumer-related lifestyle as opposed to a more austere one.

In dental education world-wide, great emphasis has been made towards a holistic approach to patient care. Diabetes has many implications on oral health and great part of the success of dental treatment is the patient's ability to manage their diabetes $[30,31,32]$. An understanding of the psychological well-being of the patient may help the dental team address concerns and in turn help their patients in dealing with their disease [18]. When the dental team is aware of the difficulty the patient experiences in controlling their glycemic levels, a more productive and positive approach may be undertaken, as well as accurate referral to psychologists if the patient displays elevated signs of distress.

\section{Conclusion}

Our brief assessment of the psychosocial impact of diabetes uncovered a complex illness. It seems quite clear that patients, whether they vocalize their feelings or not, perceive this disease as a weight and burden with which they must live. They sometimes feel isolated and dissatisfied with their caregivers. This added knowledge may help the dental team assess behaviors that indicate distress and inability to cope adopt and advocate better coping strategies for patients and, therefore, provide them with holistic care.

\section{Acknowledgment}

The authors wish to thank the Saudi Society for Diabetes for allowing us to distribute our work during their campaign.

\section{References}

1. Al-Maskari AY, Al-Maskari MY, Al-Sudairy S. Oral manifestations and complications of diabetes mellitus. Sultan Qaboos Univ Med J . 2011;11(2):179-186.

2. World Health Organization . Diabetes.2014.

3. Alqurashi KA, Aljabri KS, Bokhari SA . Prevalence of diabetes mellitus in a Saudi community. Ann Saudi Med. 2011;31(1):19-23. doi 10.4103/0256-4947.75773.

4. Cox DJ, Gonder-Frederick L. Major developments in diabetes research J Consult Clin Psychol .1992;60: 628-663.

5. Jacobson AM . The psychological care of patients with insulindependent diabetes mellitus. N Engl J Med. 1996;334:1249-1253. DOI: 10.1056/NEJM199605093341907.

6. Egede LE, Dismuke CE. Serious psychological distress and diabetes: A Review of the literature. Curr Psychiatry Rep. 2012;14(1): 15-22. doi: 10.1007/s11920-011-0240-0.

7. Polonsky WH, Anderson BJ, Lohrer PA, Welch G, Jacobson AM, Aponte JE,et al. Assessment of diabetes-related distress. Diabetes Care. 1995;18(6):754-760.

8. Mazze RS, Lucido D, Shamoon H. Psychological and social correlates of glycemic control. Diabetes Care. 1984;7(4):360-366.

9. Aikens JE, Wallander JL, Bell DS, Cole JA. Daily stress variability, learned resourcefulness, regimen adherence and metabolic control in type 1 diabetes: Evaluation of a path model. J Consult Clin Psychol. 1992;60(1): 113-118.
10. Fisher L, Glasgow R, Strycker L. The relationship between diabetes distress and clinical depression with glycemic control among patients with type 2 diabetes. Diabetes Care. 2010;33(5):10341036. doi: $10.2337 / \mathrm{dc} 09-2175$

11. Egede LE, Zheng D . Independent factors associated with major depressive disorder in a national sample of individuals with diabetes. Diabetes Care. 2003; 26(1):104-111. DOI:http://dx.doi.org/10.2337/ diacare.26.1.104

12. Powe BD, Weinrich S. An intervention to decrease cancer fatalism among rural elders. Oncol Nurs Forum.1999; 26(3):583-588.

13.Ahmed A. Cultural aspects of diabetes mellitus in Sudan. Pract Diabetes Int.2003;20(3):226-229.

14. Hjelm K, Isacsson A, Apelqvist J. Healthcare professionals' perceptions of belief about health and illness in migrants with diabetes. Pract Diabetes Int. 1998;15:233-237. DOI: 10.1002/pdi.1960150808.

15. Khoury S. Cultural approach to diabetes therapy in Middle East. Diabetes Voice. 2001;46:23-25.

16. Nichols GA, Brown JB. Unadjusted and adjusted prevalence of diagnosed depression in type 2 diabetes. Diabetes Care. 2003; 26(3):744-749. DOI: dx.doi.org/10.2337/diacare.26.3.744.

17. McDermott RA, Schmidt B, Preece C, Owens V, Taylor S, et al. Community health workers improve diabetes care in remote Australian Indigenous communities: results of a pragmatic cluster randomized controlled trial. BMC Health Services Research . 2015;15:68-75. doi: 10.1186/s12913-015-0695-5.

18. Weber P, Weberova D, Meluzinova H. How to approach to the therapy of diabetes in the elderly. Adv Gerontol. 2014;27(3):519-530.

19. Huis In‘T Veld EMJ, Makine C, Nouwen A, Karşıdağ Ç, Kadıoğlu P, et al. Validation of the Turkish version of the problem areas in diabetes scale. Cardiovasc Psychiatry and Neurol. 2011: 1-6. DOI:dx.doi. org/10.1155/2011/315068

20. Egede LE, Ellis C. Development and psychometric properties of the 12-item diabetes fatalism scale. J Gen Intern Med. 2010;25(1): 61-66. doi: 10.1007/s11606-009-1168-5.

21. Shamsaei F, Cheraghi F, Allahverdipour H. Depression in diabetic patients. J Res Health Sci. 2004;6: 39-43.

22. Anderson RJ, Freedland DK, Clouse RE, Lustman PJ. The prevalence of comorbid depression in adults with diabetes. Diabetes Care. 2001;24(6): 1069-1078.

23. Lustman PJ, Anderson RJ, Freedland KE, de Groot M, Carney RM, Clouse RE. Depression and poor glycemic control: A meta analytic review of the literature. Diabetes Care. 2000; 23(7): 934-942.

24. Sulaiman N, Hamdan A, Tamim H, Mahmood DA, Young D . The prevalence and correlates of depression and anxiety in a sample of diabetic patients in Sharjah, United Arab Emirates. BMC Fam Pract. 2010;11:80. doi: 10.1186/1471-2296-11-80.

25. Kovacs M, Mukerji P, Drash A, Iyengar S. Biomedical and psychiatric risk factors for retinopathy among children with IDDM. Diabetes Care. 1995;18(12):1592-1599.

26. Wilkinson G, Borsey DQ, Leslie P, Newton RW, Lind C, Ballinger C B . Psychiatric morbidity and social problems in patients with insulindependent diabetes mellitus. Br J Psychiatry. 1988; 153(1): 38-43.

27. Lioyd CE, Dyer PH, Barnet AH. Prevalence of symptoms of depression and anxiety in a diabetes clinic population. Diabetic Med. 2000;17(3):198-202. 
28. Taloyan M, Wajngot A, Johansson SE, Tovi J, Sundquist J. Poor self-rated health in adult patients with type 2 diabetes in the town of Södertälje: A cross-sectional study. Scand J Prim Health Care. 2010; 28(4):216-220. doi: 10.3109/00016349.2010.501223.

29. Spencer MS, Kieffer EC, Sinco BR, Palmisano G, Guzman JR, James SA, et al. Diabetes-specific emotional distress among African Americans and Hispanics with type 2 diabetes. J Health Care Poor Underserved. 2006;17(2): 88-105.
30. Ship JA. Diabetes and oral health: An overview. JADA. 2003;134: 4-10.

31. Sandberg GE, Sundberg HE, Fjellstrom CA, Wikblad KF. Type 2 diabetes and oral health: A comparison between diabetic and nondiabetic subjects. Diabetes Research and General Practice . 2000;50 (1): 27-34.

32. Ponte E, Tabaj D, Maglione M, Melato M . Diabetes Mellitus and oral disease. Acta Diabetologica. 2001; 38 (2): 57-62. 